\title{
Histological evaluation of orthodontic tooth movement following low level laser irradiation in rabbits
}

\author{
Mostafa Abtahi ${ }^{1}$, Nasrollah Saghravanian ${ }^{2}$, Maryam Poosti ${ }^{3}$, Hooman Shafaee $^{2}$
}

${ }^{1}$ Dental Research Center, Mashhad University of Medical Sciences, Mashhad, Iran

${ }^{2}$ Oral \& Maxillofacial Diseases Research Center, Mashhad University of Medical Sciences, Mashhad, Iran

${ }^{3}$ Orthodontist, Tehran, Iran

Type of article: Short article

\begin{abstract}
Background: Reduction of orthodontic treatment time is a major concern for orthodontists. Low level laser therapy (LLL) has been widely used in dentistry and it has been claimed that it could stimulate bone formation.

Objective: The aim of the present study was to evaluate histological effects of LLL on alveolar bone remodeling during experimental tooth movement in rabbits.

Methods: In this experimental study which was performed in the animal lab of Mashhad Dental School in 2016 twenty pre-pubertal female albino rabbits with the mean age of $8 \pm 1$ weeks were randomly assigned into two groups. All the rabbits were examined by a veterinarian, and underweight or diseased rabbits were excluded from the study. Fifty gram orthodontic force was applied via 0.014 stainless steel spring on central teeth in both groups. In the first group, low level laser KLO3 (wave length: $980 \mathrm{~nm}$, Power: $80 \mathrm{mw}$ ) was irradiated three minutes from the buccal aspect of central teeth for 21 days. In the second group, rabbits were not exposed to laser irradiation and served as our control group. After this period, the distance between mesial corners of incisors was measured blindly by a caliper calibrated as $0.1 \mathrm{~mm}$. All rabbits in both groups were sacrificed by vital perfusion for histological evaluation to determine the number of resorption lacuna and amount of fibrous tissue. Independent sample t-test was used to analyze the data.

Results: The number of resorption lacuna, the rate of tooth movement and fibrous tissue were significantly greater in the lased group $(\mathrm{p}=0.05)$.

Conclusion: Low level laser irradiation could accelerate tooth movement in rabbits via increased resorptive activity in alveolar bone.

Keywords: Low level laser, Tooth movement, Rabbit, Orthodontics
\end{abstract}

\section{Introduction}

Long duration of orthodontic treatment has always been of concern for many patients and clinicians. Increasing the velocity of tooth movement within physiological limits could decrease the side effects, and lead to more comfort and satisfaction for patients (1). Many modalities especially medications have been used for accelerating orthodontic tooth movement $(2,3)$. Low level laser (LLL) therapy has been used in treating many conditions with multiple clinical effects on both soft and hard tissues in dentistry. In orthodontics, the anti-analgesic effect of low-energy laser irradiation in reduction of post-adjustment pain has been recognized $(1,4)$. Some authors have exclusively concentrated on LLL as a potential stimulator of bone healing $(5,6)$. Stimulatory effects of low-energy laser irradiation on bone regeneration in rats have been noted before $(7,8)$. Guzzardella et al. observed accelerated defect healing following low power laser stimulation in rat femurs after only 3 weeks (9). In the study of Ozawa et al., it was demonstrated that laser irradiation stimulates cellular proliferation and differentiation of osteoblast cells, generating an increase in number as well as in bone formation (10). In the studies of Fujita et al. and Yamaguchi et al., it was revealed that low-energy laser irradiation accelerated tooth movement and osteoclastogenesis on the pressure site $(11,12)$. Furthermore, in the studies of Kawasaki and Shimizu, it was reported that low-energy laser

\section{Corresponding author:}

Dr. Hooman Shafaee, Oral \& Maxillofacial Diseases Research Center, Mashhad University of Medical Sciences, Mashhad, Iran. Tel: +989153162442, Email: h.shafaee@gmail.com

Received: January 30, 2017, Accepted: December 27, 2017, Published: January 2018

iThenticate screening: December 24, 2017, English editing: January 13, 2018, Quality control: January 15, 2018

This article has been reviewed / commented by four experts

(C) 2018 The Authors. This is an open access article under the terms of the Creative Commons Attribution-NonCommercialNoDerivs License, which permits use and distribution in any medium, provided the original work is properly cited, the use is non-commercial and no modifications or adaptations are made. 
irradiation stimulated the amount of tooth movement and development of osteoclasts on the pressure side during in vivo experimental tooth movement (13). Orthodontic treatment comprises biological development in which both bone formation and bone resorption are involved. However, there is still insufficient knowledge regarding the histological changes after laser irradiation on the site of tooth movement. Therefore, the present study was designed to compare histological effects of LLL on alveolar bone remodeling during experimental tooth movement with that of a control group.

\section{Material and Methods}

In this experimental study, which was performed in the animal lab of Mashhad Dental School in 2016, twenty prepubertal female albino rabbits (based on Akin's study (14) with the mean age of ( $8 \pm 1$ weeks) and the mean weight of 1850 gr were randomly divided into equal groups. In both groups orthodontic force was applied using Akin (14) and Poosti (15) methods with 0.014 stainless steel wire in the vertical slot of bonded brackets. All the springs had similar diameter and height and were activated only once from one arm to insert $50 \mathrm{gr}$ distal force. In the first group low level laser (KLO3, Mustang, Russia, wave length: $980 \mathrm{~nm}$, Power: $80 \mathrm{mw}$ ) was irradiated three minutes from the buccal aspect of the central teeth for 21 days. After this period, the distance between mesial corners of incisors was measured blindly by a caliper calibrated as $0.1 \mathrm{~mm}$. In the second group, the same method as the first group was used except that rabbits were not exposed to laser irradiation. This group served as our control group. Then all the rabbits were sacrificed by vital perfusion for histological evaluation. After fixation of maxilla in $4 \%$ formaldehyde, it was demineralized in EDTA for 60 days, dehydrated and embedded in paraffin. Serial sections were cut sagittally parallel to the long axis of the roots with $4 \mu \mathrm{m}$ diameter, and stained with hematoxylin and eosin (H\&E) to determine the number of resorption lacuna, and amount of fibrous tissue in the two groups, under light microscopy by X100 magnification. Images were subsequently captured with a digital camera coupled to the microscope, and the operator who was blind to the study groups evaluated the specimen. Statistical analysis was performed by independent-samples t-test.

\section{Results}

In this study, the number of resorption lacuna in the laser group was significantly greater than in the control group $(p=0.0005)$. Also, the amount of fibrous tissue was significantly greater in the laser group $(p=0.032)$. Our results showed that low level laser irradiation enhanced orthodontic tooth movement $(\mathrm{p}<0.01)$ (Table 1$)$. It could be seen in the $H \& E$ section that the number of resorption lacuna and fibrous tissue were greater in the laser group (Figure1).
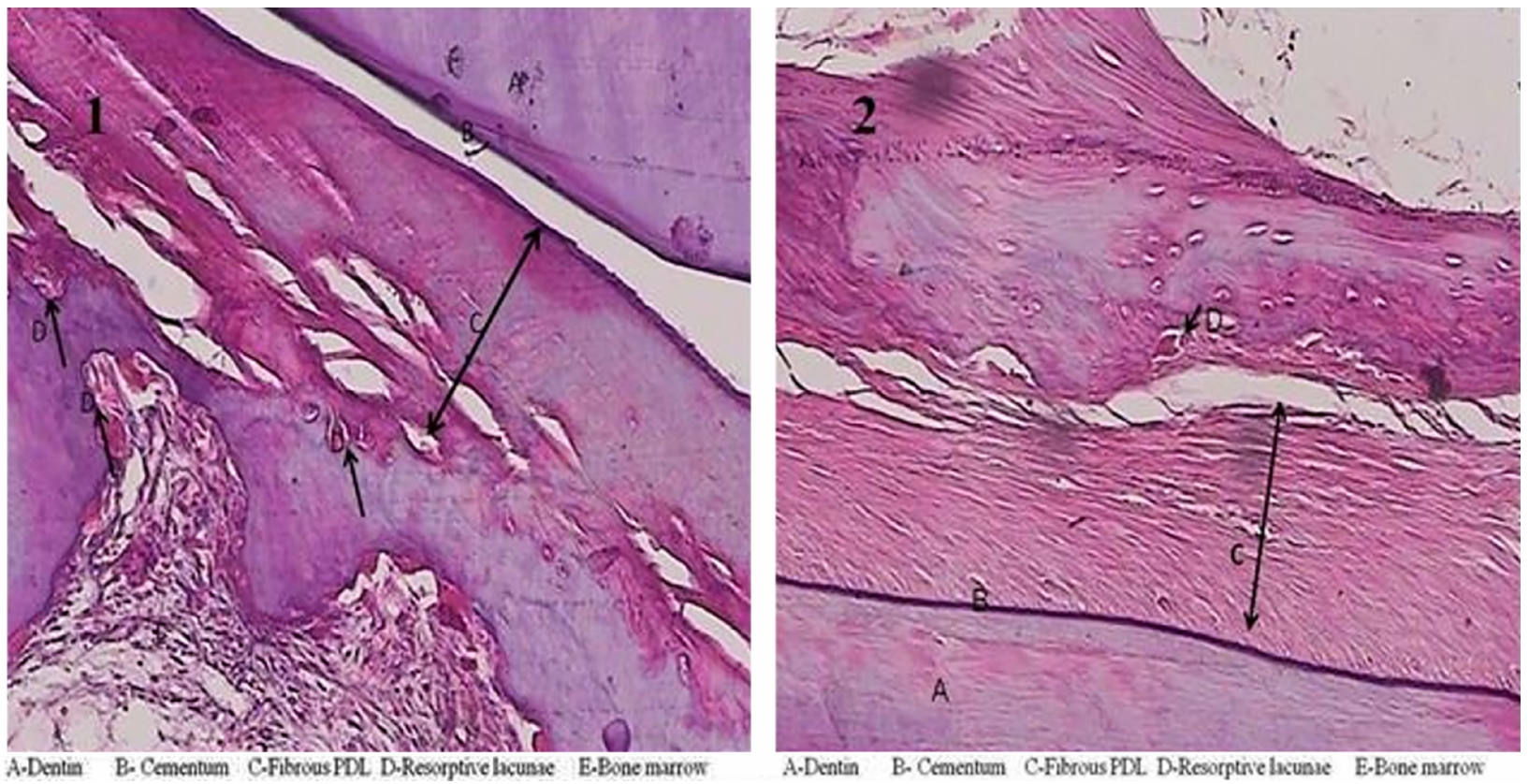

Figure 1. Histological comparison of the lased (1) and control (2) groups. A- Dentin; B: Cementum, C: Fibrous PDL, D: Resorption lacuna, E: Bone marrow 
Table 1. Comparison of Resorption lacuna, fibrous tissue and tooth movement ( $\mathrm{mm})$ in two groups

\begin{tabular}{|l|l|l|l|}
\hline Variables & Laser group $(\mathrm{Mean} \pm \mathrm{SD})$ & Control group $(\mathrm{Mean} \pm \mathrm{SD})$ & p-value \\
\hline Resorption Lacuna & $3.3 \pm 1.29$ & $1.75 \pm 1.07$ & $0.0005^{*}$ \\
\hline Fibrous tissue & $80.4 \pm 13.6$ & $67.8 \pm 10.4$ & $0.032^{*}$ \\
\hline Tooth movement $(\mathrm{mm})$ & $5.64 \pm 0.3$ & $4.5 \pm 0.41$ & $<0.001^{*}$ \\
\hline
\end{tabular}

\section{Discussion}

In this study, we evaluated the effects of KLO3 laser with the wave length of $980 \mathrm{~nm}$ and $80 \mathrm{mw}$ power on tooth movement in rabbits. We found an increased number of resorption lacuna and accelerated rate of tooth movement in the lased group in comparison with control group. Similar to our study, Fujita et al. (12) demonstrated that the rate of tooth movement after one week of low level laser irradiation was significantly greater (1.5 folds) in the lased group as compared with the control group. Kawasaki et al. (13) have also found similar results after 12 days (1.3 fold greater in lased group). In our study, the amount of tooth movement was significantly greater in the LLL group after 21 days in rabbits (1.2 fold, in comparison with control group). Youseff (16) has shown greater velocity of tooth movement in human patients with less pain during canine retraction, by irradiation of Gallium Aluminum Arsenide laser. In our study, histological evaluation showed that the number of resorption lacuna was significantly greater in the laser group and similar to our results, Cruz et al. (17) found more resorption lacuna after laser irradiation. Our histological assessment results showed that in contrary to Limpanichkul (18) findings, low level laser has adequate power to pass through soft tissues and reach alveolar bone, which is in agreement with Saito (8) and Kim (19) studies. Furthermore, low level laser does not have the disadvantage of systemic absorption, and it could be considered as a non-invasive method for acceleration of tooth movement. Conversely, Seifi et al. (20) believes that following low-level laser therapy (KLO3) with 630 and $850 \mathrm{~nm}$ wave lengths, the amounts of orthodontic tooth movement are diminished. The members of the laser group in Seifi's (20) study received laser for only 9 days but we exposed the animals to laser beam for 21 days. This difference could explain the contradiction between our result and Seifi's result. The study of Coombe et al. (21) also reported no evidence of effects on human osteosarcoma cell line (SAOS-2) while the cells were irradiated for 10 days with GaAlAs continuous wave diode laser $(830 \mathrm{~nm}$, net output of $90 \mathrm{~mW}$, energy levels of $0.3,0.5,1,2$ and $4 \mathrm{~J})$. It was determined that direct irradiation of LLL does not function as an accelerator stimulus for orthodontic tooth movement. Laser irradiation could alter blood flow in the exposed area (22), therefore it may have different effects while exposed in vital tissues rather than cell lines. However, our results showed an increase in resorption lacuna which could be explained by stimulation of osteoclastic activity in the area. These controversial findings were the main reason that our study focused on histological evaluation after laser therapy, and the methods used in this study showed that LLL therapy had a positive effect on the velocity of tooth movement in rabbits.

\section{Conclusions}

In summary, our findings showed that in the laser group, orthodontic tooth movement was significantly more than in the control group and also, resorption lacuna were greater in the laser group. These findings may indicate that application of LLL in orthodontic clinics may accelerate the rate of tooth movement and decrease the duration of treatment. Finally, we suggest that other types of LLL and other protocols of irradiation be used in future studies.

\section{Acknowledgments:}

The authors would like to extend their appreciation to the Vice Chancellor for Research of Mashhad University of Medical Sciences for the financial support.

\section{Conflict of Interest:}

There is no conflict of interest to be declared.

\section{Authors' contributions:}

All authors contributed to this project and article equally. All authors read and approved the final manuscript.

\section{References:}

1) Lim HM, Lew KK, Tay DK. A clinical investigation of the efficacy of low level laser therapy in reducing orthodontic post adjustment pain. Am J Orthod Dentofacial Orthop. 1995; 108: 614-22. doi: 10.1016/S0889-5406(95)70007-2. 
2) Abtahi M, Shafaee H, Saghravania N, Peel S, Giddon D, Sohrabi K. Effect of corticosteroids on orthodontic tooth movement in a rabbit model. J Clin Ped Dent. 2014; 38(3): 285-9. doi: 10.17796/jcpd.38.3.n04h7105121663t6. PMID: 25095326.

3) Mirhashemi AH, Akhoundi MS, Sheikhzadeh S, Momeni N, Dehpour A, Alaeddini M, et al. Effect of fluoxetine consumption on orthodontic tooth movement in rats. J Dent. 2015; 12(12): 882-9.

4) Abtahi SM, Mousavi SA, Shafaee H, Tanbakuchi B. Effect of low-level laser therapy on dental pain induced by separator force in orthodontic treatment. Dent Res J (Isfahan). 2013; 10(5): 647-51. PMID: 24348624, PMCID: PMC3858741.

5) Tang XM, Chai BP. Effects of $\mathrm{CO} 2$ laser irradiation on experimental fracture healing: a transmission electron microscopic study. Lasers Surg Med. 1986; 6: 346-52. doi: 10.1002/lsm.1900060309. PMID: 3090390.

6) Trelles MA, Mayayo E .Bone fracture consolidates faster with low-power laser. Lasers Surg Med. 1987; 7: 36-45. doi: 10.1002/1sm.1900070107. PMID: 3573935.

7) Barushka O, Yaakobi T, Oron U. Effect of low-energy laser ( $\mathrm{He} . \mathrm{Ne})$ irradiation on the process of bone repair in the rat tibia. Bone. 1995; 16: 47-55. PMID: 7742082.

8) Saito S, Shimizu N. Stimulatory effects of low-power laser irradiation on bone regeneration in midpalatal suture during expansion in the rat. Am J Orthod Dentofacial Orthop. 1997; 111: 525-32. doi: 10.1016/S0889-5406(97)70152-5. PMID: 9155812.

9) Guzzardella GA, Fini M, Torricelli P, Giavaresi G, Giardino R. Laser stimulation on bone defect healing: An In Vitro Study. Lasers Med Sci. 2002; 17: 216-20. doi: 10.1007/s101030200031. PMID: 12181636.

10) Ozawa Y, Shimizu N, Kariya G, Abiko Y. Low-energy laser irradiation stimulates bone nodule formation at early stages of cell culture in rat calvarial cells. Bone. 1998; 22: 347-54. doi: 10.1016/S87563282(97)00294-9. PMID: 9556134.

11) Yamaguchi M, Fujita S, Yoshida $T$, Oikawa K, Yamamoto H, Kasai K. Low-energy laser irradiation stimulates the tooth movement velocity via expression of M-CSF and c-fms. Orthod Waves. 2007; 66: 13948. doi: 10.1016/j.odw.2007.09.002.

12) Fujita S, Yamaguchi Y, Utsunomiya T, Yamamoto H, Kasai K. Low-energy laser irradiation stimulates tooth movement velocity via expression of RANK and RANKL. Orthod Craniofac Res. 2008; 11: 143-55. doi: 10.1111/j.1601-6343.2008.00423.x. PMID: 18713151

13) Kawasaki K, Shimizu N. Effects of low-energy laser irradiation on bone remodeling during experimental tooth movement in rats. Lasers Surg Med. 2000; 26: 282-91. doi: 10.1002/(SICI)10969101(2000)26:3<282::AID-LSM6>3.0.CO;2-X. PMID: 10738291.

14) Akin E, Gurton AU, Olmez H. Effects of nitric oxide on orthodontic tooth movement in rats. Am J Orthod Dentofacial Orthop. 2004; 126(5): 608-14. doi: 10.1016/S0889540604004494. PMID: 15520694.

15) Poosti M, Basafa M, Eslami N. Progesterone effects on experimental tooth movement in rabbits. J Calif Dent Assoc. 2009; 37: 483-6. PMID: 19653405.

16) Youssef M, Ashkar S, Hamade E, Gutknech N, Lomper TF, Mir M. The effect of low level laser therapy during orthodontic movement: a preliminary study. Lasers Med Sci. 2007; 23: 27-33. PMID: 17361391.

17) Cruz DR, Kohata EK, Ribeiro MS, Wetter NU. Effects of low intensity laser therapy on the orthodontic movement velocity of human teeth: a preliminary study. Lasers Surg Med. 2004; 35: 117-20. doi: 10.1002/1sm.20076. PMID: 15334614.

18) Limpanichkul W, Godfrey K, Srisuk N, Rattanayatikul C. Effects of low-level laser therapy on the rate of orthodontic tooth movement. Orthod Craniofac Res. 2006; 9: 38-43. doi: 10.1111/j.16016343.2006.00338.x. PMID: 16420273.

19) Kim YD, Song WW, Kim SS, Kim GC, Hwang DS, Shin SH, et al. Expression of receptor of nuclear factor-KB ligand, receptor activator of nuclear factor-KB, and osteoprotegerin, following low-level laser treatment on deproteinized bovine bone graft in rats. Lasers Med Sci. 2009; 24: 577-84. doi: 10.1007/s10103-008-0614-7. PMID: 18825474.

20) Seifi M, Shafeei HA, Daneshdoost S, Mir M. Effects of two types of low level laser wave lengths ( 850 and $630 \mathrm{~nm})$ on the orthodontic tooth movements in rabbits. Lasers MedSci. 2007; 22: 261-4. doi: 10.1007/s10103-007-0447-9. PMID: 17334676.

21) Coombe AR, Ho CT, Darendeliler MA, Hunter N, Philips JR, Chapple CC, et al. The effect of low level laser on osteoblastic cells. Clin Orthod Res. 2001; 1: 3-14. PMID: 11553080.

22) Song CW, Chelstrom LM, Levitt SH, Haumschild DJ. Effects of temperature on blood circulation measured with the laser Doppler method. Int J Radiat Oncol Biol Phys. 1989; 17: 1041-7. doi: 10.1016/0360-3016(89)90153-3. PMID: 2808037 